\title{
Prevalence and Associated Factors of Attention Deficit Hyperactivity Disorder (ADHD) in a Rural Community, Central Thailand: A Mixed Methods Study
}

\author{
Boonsub Sakboonyarat ${ }^{1}$, Kritchaporn Chokcharoensap ${ }^{1}$, Nadcha Sathuthum ${ }^{1}$, Soraya Chutchawalanon ${ }^{2}$, \\ Chawengsak Khamkaen ${ }^{1}$, Wetawit Sookkaew ${ }^{1}$, Jutatip Thamwinitchai ${ }^{1}$, Natthanon Phalakornkul ${ }^{1}$, Sila Saelim $^{1}$, \\ Pongpat Liwvorakul ${ }^{1}$, Pornpun Khaengkhun ${ }^{1}$, Patcharee Dilokkulwattana ${ }^{1}$, Poomwit Puttakiaw ${ }^{1}$, \\ Monai Meesaeng ${ }^{1}$, Orasit Sukreeyapongse ${ }^{1}$, Nond Minanond ${ }^{1} \&$ Ram Rangsin ${ }^{3}$ \\ ${ }^{1}$ Phramongkutklao College of Medicine, Bangkok, Thailand \\ ${ }^{2}$ Department of Pediatrics, Phramongkutklao College of Medicine, Bangkok, Thailand \\ ${ }^{3}$ Department of Military and Community Medicine, Phramongkutklao College of Medicine, Bangkok, Thailand \\ Correspondence: Boonsub Sakboonyarat, Department of Military and Community Medicine, Phramongkutklao \\ College of Medicine, 315 Ratchawithi Rd Ratchathevi BKK 10400, Thailand. Tel: 66-85-95-45955. E-mail: \\ boonsub1991@pcm.ac.th, countryside.physician@gmail.com
}

Received: December 23, 2017 Accepted: January 27, 2018 Online Published: February 9, 2018

doi:10.5539/gjhs.v10n3p60

URL: https://doi.org/10.5539/gjhs.v10n3p60

\begin{abstract}
Background: Attention Deficit Hyperactivity Disorder (ADHD) is one of the most common behavioral problems among children around the world including Thailand. The disease affects their life, parents and community when left untreated. Most information concerning ADHD in Thailand derives from hospital based studies. The present study aimed to determine the prevalence and associated factors of ADHD in a remote rural community.

Methods: A total of 495 primary school children were screened using the SNAP-IV. Positive screening cases were then diagnosed by pediatric psychiatrists according to the DSM-V criteria. Standardized questionnaires were used to collect demographic data and associated factors. A qualitative study using focus group discussions and indepth interviews was conducted to determine knowledge and perceptions regarding ADHD among teachers and main guardians.

Results: The prevalence of ADHD among children was $2.2 \%$. Univariate and multivariate analysis showed that children with ADHD were associated with both familial and individual factors including being repeatedly inattentive or hyperactive in class, suspended from school, and changing school, a history of bullying and main guardians were not parents. Qualitative data showed that both main guardians and teachers had inadequate knowledge and misperceptions regarding children with ADHD. The local health care system could not detect this problem so the children with ADHD were not properly treated.
\end{abstract}

Conclusion: Our data emphasized that ADHD was a problem in this remote rural community. Screening tests and referral systems for ADHD should be provided for rural communities.

Keywords: Attention Deficit Hyperactivity Disorder, ADHD, prevalence, associated factors, rural community, Thailand, mixed methods

\section{Introduction}

Attention Deficit Hyperactivity Disorder (ADHD) is one of the most common mental disorders that develop in children and becomes apparent in preschool and early school years. (Al Hamed et al., 2008) The three predominant subtypes include inattention, hyperactivity-impulsivity and combined inattentive/hyperactive impulsive subtype (combined ADHD)(Homer et al., 2000). The diagnosis of ADHD is based on criteria specified by the Diagnostic and Statistical Manual of Mental Disorders, Fourth Edition (DSM-IV). (Homer et al., 2000) ADHD was diagnosed in 4.0 to $29.7 \%$ of children aged between 6 to 12 years in different geographical areas (Brown et al., 2001; Thomas et al., 2015). In Thailand, one behavioral survey among 7,188 Thai students in grades 1-5 conducted in 2012 estimated the prevalence of ADHD at $8.1 \%$ (Visanuyothin et al., 2013).

Several family-related factors such as high birth order, large family size and living with a single parent were shown 
to be associated with ADHD symptoms (Abolfotouh et al., 1997; Herrerias, Perrin, \& Stein, 2001; Trangkasombat, 2008; Hurtig et al., 2007; Wehmeier, Schacht, \& Barkley, 2010). Other factors including low birth weight and artificial infant feeding have also been shown to be significantly associated with ADHD (Sasaluxnanon \& Kaewpornsawan, 2005; Nigg \& Breslau, 2007). Children with ADHD are associated with a broad range of negative outcomes including depression, school failure and dropout, learning disabilities, conduct disorders among children and adults, failed relationships, workplace underachievement, substance abuse and low self-esteem among adults (Austerman, 2015; van der Meeret et al., 2012).

Nevertheless, the information of ADHD in Thailand is still limited especially in rural communities. Most studies were hospital- or school-based in urban populations (Charnsil \& Sriapai, 2011; Muanprasart et al., 2014; Visanuyothin et. al., 2013; Yajai Sitthimongkol \& Apinuntavech, 2012). The study aimed to determine the prevalence and associated factors of ADHD in a remote rural community, central Thailand. In addition, a qualitative study was also conducted to determine knowledge and perceptions of teachers and main guardians toward children with ADHD in this community.

\section{Method}

\subsection{Study Populations}

The present study was conducted in 2 primary schools in a rural community, Chachoengsao, central Thailand, 154 $\mathrm{km}$ east from Bangkok. This remote, isolated community totaled 8,777 villagers, mostly farmers. This study employed a mixed-methods design. A cross-sectional quantitative study identified the prevalence and associated factors of ADHD. A total survey was performed including 158 students in school No. 1 and 377 students in school No. 2. In addition, a qualitative study determined knowledge and perceptions of teachers and main guardians of the children with ADHD. Purposive sampling was also used to select the main guardians of the children who were diagnosed with ADHD for indepth interviews. A total of 15 teachers from =school No. 1 and 21 teachers from the school No. 2 were purposively selected for focus group discussions.

\subsection{Detection and Characterization of Children with ADHD}

The SNAP-IV Rating Scale, a revision of the Swanson, Nolan and Pelham (SNAP) Questionnaire (Swanson et al., 1992) was conducted to screen the ADHD condition among these children. The items from the DSM-IV (1994) criteria for Attention-Deficit/Hyperactivity Disorder (ADHD) were included for two subsets of symptoms: inattention and hyperactivity/impulsivity (APA, 1994). The Thai version of SNAP-IV showed favorable reliability (Cronbach's alpha: SNAP-IV $=0.93-0.96$ ). Both SNAP-IV scales completed by parents and by teachers proved useful in the screening of ADHD (AUC: SNAP-IV = 0.71-0.81) (AUC: SNAP-IV =0.55-0.67) (Pityaratstian N et al., 2014). In addition, items were included from the DSM-IV criteria for Oppositional Defiant Disorder. The SNAP-IV is based on a 0 to 3 rating scale (Not at all $=0$, Just a little $=1$, Quite a bit $=2$, and Very much $=3$ ). Subscale scores on the SNAP-IV are calculated by summing the scores on the items in the subset and dividing by the number of items in the subset. The score for any subset is expressed as the average rating-per-item. Both teachers and main guardians had to complete the SNAP-IV. A positive screening of the disease requires a positive result from both SNAP-IV for teachers and main guardians. The result of SNAP-IV separated the included children in 2 groups, i.e., children with negative and positive result of SNAP-IV. The children with positive results were considered at high risk of ADHD and needed to meet pediatric psychiatrists to find a definite diagnosis as indicated in the DSM-V. When ADHD was diagnosed, specialists would give counseling to their guardians about how to understand, manage, and obtain appropriate treatment for their child. On the other hand, for those without a diagnosis of ADHD but showing a positive result on the SNAP-IV, the specialists would recommend how to observe and take care of their child. To determine the associated factors of ADHD among these children, a face-to-face interview using standardized questionnaires was conducted among the main guardians. The questionnaires covered demographic information of children and their parents, children's behaviors and school performance and parents' behaviors.

For the qualitative part, the teachers and main guardians of the ADHD child were purposively selected to participate in focus group discussions or indepth interviews. For indepth interview, 8 main guardians of ADHD children were selected to participate. A total of 12 of the teachers in both schools were selected for the focus group discussion. The conversation was recorded using a voice recorder and recorded conversations were transcribed into text. The data was collected continuously until the contents were saturated

\subsection{Data Analysis}

For the quantitative study, collected data were checked for accuracy and completeness and were coded and entered using STATA/MP12. Demographic, behavioral data and prevalence was analyzed using descriptive statistics. 
Binary logistic regression analysis was used to determine the associated factors of ADHD. The magnitude of association was presented as crude and adjusted odds ratios (ORs) with a $95 \%$ confidence interval. The $p$-value of less than 0.05 was considered as statistically significant in this study. For the qualitative study, the text-based data transcribed from the conversation were sorted and coded. Data were revised, organized and summarized for analysis. The methods used included content analysis, direct quotations and selected words to give consideration to actual local words used by the participants.

\subsection{Ethical Considerations}

This study was reviewed and approved by the Institutional Review Board, Royal Thai Army Medical Department. Consent forms were completed by the main guardian of each child before they participated in the study. For the process of focus group discussion and indepth interview, the questions were treated sensitively and confidentially. When the participants were worried about any question, they did not have to answer. For the children diagnosed with ADHD, this diagnosis was kept for confidential and not disclosed publicly.

\subsection{Operational Definitions and Abbreviations}

$\mathrm{ADHD}=$ Attention Deficit Hyperactivity Disorder

DSM-V = Diagnostic and Statistical Manual of Mental Disorders, Fifth Edition

\section{Results}

\subsection{Quantitative Study Determining the Prevalence and Associated Factors of ADHD}

Of 535, 495 students $(92.5 \%)$ were included in this study. Demographic data of these children are shown in Table 1. In all, 254 (51.3\%) were female. The average age of the participants was $9.54 \pm 1.75$ years (range from 6 to 13 ). The participants studied in grade one to grade six. Using the SNAP-IV, $79(16 \%)$ and 93 students $(17.3 \%)$ were positive evaluated by the main guardians and teachers, respectively. A positive result in both main guardian and teacher's evaluation were identified among 33 students (6.7\%). Of 33, 30 students were allowed to meet specialists for definite diagnosis. ADHD was identified among 11 students. Other conditions including mental retardation, learning disability with mental retardation, slow learner were diagnosed among 6 students. Thus, the prevalence of ADHD in this population was $2.2 \%$. The prevalence of ADHD in each subgroup and univariate logistic regression analysis for factors associated with ADHD children are shown in Table 1.

Multivariate logistic regression analysis was performed to identify the associated factors of ADHD (Table 2). The associated factors of ADHD included both familial and individual factors. Having a relative as a main guardian, having a history of repeating class, inschool suspension, changing school and having a history of bullying was significantly associated with ADHD

\subsection{Qualitative Study of ADHD in the Community}

For indepth interviews, data were collected from a total of 8 main guardians including 1 father, 1 mother and 6 relatives. For focus group discussions, data were collected from a total of 12 teachers including 4 males and 8 females with ages ranging from 25 to 44 years old. The mean duration of teaching experience was 4 years (range from 1 to 10 years).

\subsubsection{Knowledge and Perception of ADHD in Teachers and Guardians}

All parents did not know that their children had ADHD. In addition, they did not know ADHD as a mental health problem. They just perceived that these children had negative behaviors such as being stubborn, naughty, overactive, forgetful, agitated, often lost, slow to process information, having difficulty in waiting, and exhibiting roles of martyrs, thieves and ringleaders. A mother of an ADHD child said,

"He is obstinate and never ever stays still and climbs up tree after tree. He is just going right away after we tell him not to."

Teachers did not exactly know whether these children had negative behaviors or disease. However, they noticed that these students had problems concentrating in class, working in groups, succeeding in their assignments and showing ignorance. In addition, these children also exhibited emotional problems such as aggressiveness and uncontrolled mood. As a teacher said,

"To do nothing is not successful, to motivate them to work at all."

Most guardians did not know the causes of the negative behaviors expressed by these children. They guessed that it could be the result of alcohol consumption during pregnancy, lack of antenatal care, parental drug abuse, child abuse, parental child care etc. However, they noticed that some of these children's relatives also showed these 
negative behaviors. The teachers gave possible causes including genetics, poor family and community environment, imitative behavior, hormonal or chemical disturbance, alcohol consumption during pregnancy, abnormal eating behaviors etc. Genetics and poor family and community environment were strongly suggested as causes of the negative behaviors by these teachers.

The perceptions toward these children differed among their guardians. The majority of guardians perceived that these children exhibited negative behaviors without knowing whether they had a disease. Some misunderstood these children had other mental disorders such as autism and mental retardation. However, some guardians thought that these children were normal as they said that,

"He thinks like a child, just not restless. Actually it is not only him, the other kids are like this."

Most teachers believed that the children with these negative behaviors should be treated. Similar to the guardian group, some considered these children as normal.

\subsubsection{Effects on ADHD Children}

Most guardians thought that these children could not pay attention in class and eventually could not read or write. Some guardians said that,

"A grandmother complained that her grandchild only read and wrote only for a short while and could not finish the homework properly. He also did the same thing at school."

Teachers pointed that these children could not perform well in studying and lacked logical thinking skills. These children were also irresponsible and unable to be disciplined causing problems in their daily life activities. These children were easily influenced by others and became negative. The teachers thought that they were unable to control themselves, properly communicate and express themselves to other people. For example, a teacher said,

"The performance of these children was poor at school. I do not want to send them to the Ordinary National Education Test (O-NET), because it will make a lower school assessment result.

\subsubsection{Effects on the Family}

The negative behaviors of these children such as aggressiveness caused difficulty in taking care of these children. The situation resulted in disharmony in the family and even broken homes. Because rural communities in Thailand usually comprise extended families, the children from unsettled homes may have lived with their relatives.

"Her mom left her because she was so difficult." "Her dad took her but could not stand her."

"So grandma now takes care of her"

"Living with the family, he always quarrels with father, mother and sister." "He was very aggressive for example using a knife on them. However, he was very calm with his aunt; that's why he was living with his aunt."

These children often blamed other family members, even their parents. The teachers also shared that these children felt inferior and were viewed as a burden to the family. This was often seen when these children caused troubles or when they misbehaved. The problems led their parents to family conflicts and unfortunately caused broken families in some situations.

\subsubsection{Effects on Community}

Some behaviors of these children might be imitated by their friends at school. Some guardians said that these children behaved aggressively with their teachers. Teachers said that they did not pay the attention to their work, were exploitative and unable to work with their friends. Some were hated and annoyed by their friends. Sometimes they brought their friends into trouble. Both guardians and teachers shared the same opinion that these children would cause social problems such as stealing, fighting, vandalism, drug addiction and were rejected by society.

\subsubsection{Expectations of Teachers and Guardians}

Guardians expected that their children could grow up better, learn as much as they could, get an appropriate job and live a better life. For example, one parent said,

"I don't want anything else. I just want my son to grow up and be able to take care of himself." Teachers expected these children to perform well in class like other students and to be able to adapt to society. For example, one teacher said,

"I want them to improve their learning skills." 


\subsubsection{Diagnosis and Treatment of ADHD Children}

The local health care unit in this community could not diagnose and treat this condition. No screening for ADHD was conducted among these children until this study. Both guardians and teachers did not know any specific treatments. Some assumed that the way to improve these children might include medication, behavioral adaptation and meditation. Some guardians were uncertain in seeking diagnosis and treatment because of economic problems. To obtain diagnosis and treatment, they had to access a higher level of health care institute where pediatric psychiatrists are available. Although they were covered by the Universal Coverage Health Scheme, they had to spend some money for travelling.

Table 1. Univariate logistic regression analysis for factors associated ADHD in a rural community, Thailand

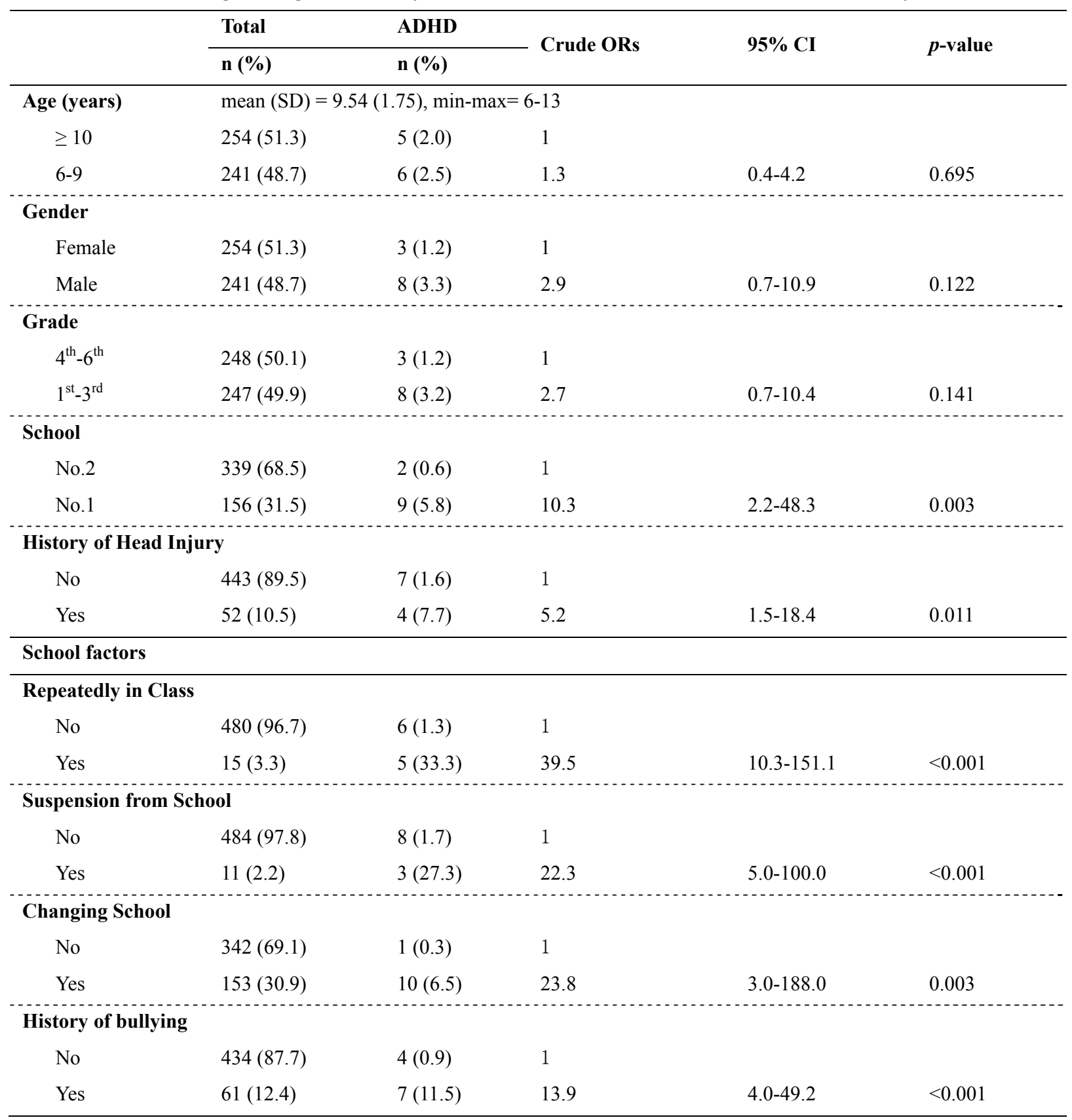




\section{Family factors}

\begin{tabular}{|c|c|c|c|c|c|}
\hline \multicolumn{6}{|l|}{ Family status } \\
\hline Family (both parents) & $311(64.5)$ & $6(1.9)$ & 1 & & \\
\hline One of the parents & $171(35.5)$ & $5(2.9)$ & 1.5 & $0.5-5.1$ & 0.487 \\
\hline \multicolumn{6}{|l|}{ Main guardian } \\
\hline Father/mother & $302(61.6)$ & $2(0.7)$ & 1 & & \\
\hline Relative & $188(38.4)$ & $9(4.8)$ & 7.5 & $1.6-35.3$ & 0.01 \\
\hline \multicolumn{6}{|l|}{ Siblings } \\
\hline One or more sibling & $396(82.7)$ & $7(1.8)$ & 1 & & \\
\hline No sibling & $83(17.3)$ & $3(3.6)$ & 2.1 & $0.5-8.2$ & 0.295 \\
\hline \multicolumn{6}{|l|}{ Education (main guardian) } \\
\hline Primary or above & 463 (94.9) & $8(1.7)$ & 1 & & \\
\hline Uneducated & $25(5.1)$ & $3(12.0)$ & 7.8 & $1.9-31.3$ & 0.004 \\
\hline \multicolumn{6}{|c|}{ Disharmony between parents } \\
\hline No & $427(86.3)$ & $8(1.9)$ & 1 & & \\
\hline Yes & $68(13.7)$ & $3(4.4)$ & 2.4 & $0.6-9.3$ & 0.201 \\
\hline \multicolumn{6}{|l|}{ Maternal factors } \\
\hline \multicolumn{6}{|l|}{ Lie as a habit } \\
\hline No & $448(95.3)$ & $9(2.0)$ & 1 & & \\
\hline Yes & $22(4.7)$ & $2(9.1)$ & 5.5 & $1.0-24.0$ & 0.052 \\
\hline \multicolumn{6}{|c|}{ Alcohol consumption during pregnancy } \\
\hline No & $477(96.4)$ & $9(1.9)$ & 1 & & \\
\hline Yes & $18(3.6)$ & $2(11.1)$ & 6.5 & $1.3-32.6$ & 0.023 \\
\hline \multicolumn{6}{|c|}{ Smoking during pregnancy } \\
\hline No & $485(98.0)$ & $10(2.1)$ & 1 & & \\
\hline Yes & $10(2.0)$ & $1(10.0)$ & 5.3 & $0.6-45.7$ & 0.131 \\
\hline \multicolumn{6}{|l|}{ Paternal factors } \\
\hline \multicolumn{6}{|l|}{ Lie as a habit } \\
\hline No & $443(92.9)$ & $8(1.8)$ & 1 & & \\
\hline Yes & $34(7.1)$ & $3(8.8)$ & 5.3 & $1.3-20.8$ & 0.018 \\
\hline
\end{tabular}


Table 2. Multivariate logistic regression analysis for factors associated ADHD in a rural community, Thailand

\begin{tabular}{|c|c|c|c|c|c|}
\hline & \multirow{2}{*}{$\begin{array}{l}\text { Total } \\
\text { n (\%) }\end{array}$} & \multirow{2}{*}{$\begin{array}{l}\text { ADHD } \\
\text { n (\%) }\end{array}$} & \multirow{2}{*}{$\begin{array}{l}\text { Adjusted } \\
\text { ORs }\end{array}$} & \multirow{2}{*}{$95 \% \mathrm{CI}$} & \multirow{2}{*}{$p$-value } \\
\hline & & & & & \\
\hline \multicolumn{6}{|l|}{ Repeatedly in Class } \\
\hline No & $480(96.7)$ & $6(1.3)$ & 1 & & \\
\hline Yes & $15(3.3)$ & $5(33.3)$ & 20.7 & $1.9-226.1$ & 0.013 \\
\hline \multicolumn{6}{|c|}{ Suspension from School } \\
\hline No & $484(97.8)$ & $8(1.7)$ & 1 & & \\
\hline Yes & $11(2.2)$ & $3(27.3)$ & 49.5 & $4.0-615.5$ & 0.002 \\
\hline \multicolumn{6}{|l|}{ Changing School } \\
\hline No & $342(69.1)$ & $1(0.3)$ & 1 & & \\
\hline Yes & $153(30.9)$ & $10(6.5)$ & 31.4 & $2.1-463.8$ & 0.012 \\
\hline \multicolumn{6}{|l|}{ History of bullying } \\
\hline No & $434(87.7)$ & $4(0.9)$ & 1 & & \\
\hline Yes & $61(12.4)$ & $7(11.5)$ & 22.8 & $3.3-156.0$ & 0.001 \\
\hline \multicolumn{6}{|l|}{ Main guardian } \\
\hline Father/mother & $302(61.6)$ & $2(0.7)$ & 1 & & \\
\hline Relative & $188(38.4)$ & $9(4.8)$ & 8.3 & $1.1-60.7$ & 0.038 \\
\hline
\end{tabular}

Backward Wald: Adjusted for school, grade, gender, history of bullying, changing school, suspension from school, repeatedly in class, main guardians, education and incomes of the main guardian, having a father or mother who tells a lie as a habit, smoking or alcoholic pregnancy, disharmony between parents, and history of head injuries.

\section{Discussion}

The prevalence of ADHD in the present study was $2.2 \%$, which is relatively low compared with the related studies in Thailand (Visanuyothin et al., 2013; Benjasuwantep, Ruangdaraganon, \& Visudhiphan, 2002). A recent study (Visanuyothin et al., 2013) conducted among 7,188 school children to determine the situation of ADHD in Thailand used a three-stage stratified cluster sampling (provinces, schools and classrooms) and showed an overall prevalence of $8.1 \%$. The prevalence in Thailand was similar to that reported from another Southeast Asian country, Vietnam (Pham, Nguyen, \& Tran, 2015). The prevalence of ADHD differed according to the part of Thailand, i.e., $5.1 \%$ in the north, $6.5 \%$ in Bangkok, $6.7 \%$ in the central regions, $9.4 \%$ in the northeast and $11.7 \%$ in the south. Another study in Bangkok (Benjasuwantep, Ruangdaraganon, \& Visudhiphan, 2002) showed a prevalence of 6.5\% in one school. The relatively low prevalence of ADHD in the present study might be the result of the limited population in a remote rural area. A recent study from Vietnam also showed that the prevalence of ADHD among children living in rural areas was 2.2 times lower than those who lived in urban areas (Pham, Nguyen, \& Tran, 2015). This might have indicated that a few risk factors for ADHD such as environmental exposure, complications of pregnancy and delivery and psychosocial adversity may vary in different settings (Benjasuwantep, Ruangdaraganon, \& Visudhiphan, 2002). Most studies found that ADHD was more common among males (Thapar \& Cooper, 2016). In the present study, the prevalence of ADHD among boys tended to be higher but not statistically significant, which could have been due to the small sample size.

The children with ADHD in this community were associated with problems in school including educational and social aspects. They were significantly associated with repeating classes, suspension from school and changing schools. Our qualitative data indicated that ADHD children could not pay attention in class and eventually could not read or write. ADHD children lacked logical thinking skills, concentration, responsibility and discipline, which consequently led to failures in studying, working or problem solving in daily life activities. In addition to their study ability, bullying behavior of some children with ADHD might be associated with their suspension from school. These children were easily influenced by others, unable to control themselves and became negative leading to bullying behaviors. Some children exhibited aggressive, mischievous behaviors until the teachers had to meet their parents. 
A related study (Hurtig et al., 2007) indicated that children with ADHD commonly lived in nonintact families. Our finding showed that the children with ADHD in this rural community were also associated with living with relative(s), and not having parents as their main guardians. From the qualitative information, children with ADHD might be the cause of family problems. In Thailand, rural communities usually comprise extended families in which the relatives are living together or in the same areas. Some children were neglected by their parents. Thus, their relatives were commonly responsible for these children.

Although most interviewed guardians and teachers were experienced with ADHD children, they did not exactly know their conditions especially in the guardian group. Some teachers might know about ADHD from some training courses, but they did not know how to differentiate ADHD from normal child behaviors of these age groups. In addition, no screening or diagnostic system was available in these schools and local healthcare center of this community. Thus, these ADHD children lacked proper diagnosis, referrals and specific treatment. Knowledge of ADHD such as symptoms, screening tests and specific treatments should be provided to the community. This condition should also be emphasized among teachers who might be one of the first to notice ADHD symptoms. The chance for receiving proper diagnosis and treatment will be increased and the consequences of ADHD will be reduced.

To date, a few screening tests (Alda \& Serrano-Troncoso, 2012) for ADHD are available and suitable for using at the community level. From our experience of SNAP-IV for screening ADHD in this community, the test was easy to use and understand by both guardians and teachers. Using this screening test should be the principle intervention for identifying ADHD at the community level, which could lead the suspected children to the proper healthcare system. In addition, ADHD is considered a chronic condition for which continuous care is needed. Local healthcare centers should not only prepare a detection and referral system but also use the chronic care model for these children. In Thailand, pediatric psychiatrists are limited to only tertiary healthcare centers, so follow-up care and treatment adherence should also be enhanced by the local healthcare center.

The limitation in this study was that only school children were included. From the qualitative information, ADHD children in this community were unknown or considered to have a disease. Some might have been suspended or expelled from school. This could have caused the relatively low prevalence of ADHD among children in this remote rural community compared with schools in urban communities where ADHD is more familiar and supported.

In conclusion, we presented here the situation of ADHD in a remote rural community, Thailand. ADHD in this community was associated with educational problems and mischievous behaviors. The main guardians of these children were usually not their parents. Knowledge of ADHD was limited causing misperceptions towards these children. In addition, no screening or diagnostic system was available in this community. Our information is crucial for the healthcare system to improve screening and referral systems at the community level.

\section{Acknowledgments}

We wish to thank Asst. Prof. Nuttorn Pityaratstian from the Department of Psychiatry, Chulalongkorn University for permission to use the SNAP-IV, Thai version. We thank the staff at the Department of Pediatrics, Phramongkutklao Hospital and the College of Medicine, for their support in completing this study. We also wish to thank Professor Colonel Mathirut Mungthin for support and for proofreading this manuscript.

\section{Complete Interests Statement}

The authors declare they have no competing or potential conflicts of interest.

\section{References}

Abolfotouh, M. A. (1997). Behaviour disorders among urban schoolboys in south-western Saudi Arabia.

Alda, J. A., \& Serrano-Troncoso, E. (2012). Attention-deficit hyperactivity disorder: agreement between clinical impression and the SNAP-IV screening tool. Actas espanolas de psiquiatria, 41(2), 76-83. PMID: 23592067.

Al Hamed, J. H., Taha, A. Z., Sabra, A. A., \& Bella, H. (2008). Attention deficit hyperactivity disorder (ADHD) among male primary school children in Dammam, Saudi Arabia: prevalence and associated factors. $J$ Egypt Public Health Assoc, 83(3-4), 165-182. PMID: 19302773.

American Psychiatric Association. (1994). Diagnostic and statistical manual of mental disorders (DSM) (pp. 143-147). Washington, DC: American psychiatric association.

Austerman, J. O. S. E. P. H. (2015). ADHD and behavioral disorders: Assessment, management, and an update from DSM-5. Cleveland Clinic journal of medicine, 82(11 Suppl 1), S2-S7. 
https://doi.org/10.3949/ccjm.82.s1.01

Banerjee, T. D., Middleton, F., \& Faraone, S. V. (2007). Environmental risk factors for attention - deficit hyperactivity disorder. Acta paediatrica, 96(9), 1269-1274. https://doi.org/10.1111/j.16512227.2007.00430.x

Benjasuwantep, B., Ruangdaraganon, N., \& Visudhiphan, P. (2002). Prevalence and clinical characteristics of attention deficit hyperactivity disorder among primary school students in Bangkok. Journal of the Medical Association of Thailand = Chotmaihet thangphaet, 85, S1232-40. PMID:12549800.

Brown, R. T., Freeman, W. S., Perrin, J. M., Stein, M. T., Amler, R. W., Feldman, H. M., . . . Wolraich, M. L. (2001). Prevalence and assessment of attention-deficit/hyperactivity disorder in primary care settings. Pediatrics, 107(3), e43-e43. https://doi.org/10.1542/peds.107.3.e43

Charnsil, C., \& Sriapai, P. (2011). Attention deficit hyperactivity symptoms in children with autistic disorder: A cross-sectional descriptive study. Journal of the Medical Association of Thailand=Chotmaihet thangphaet, 94(2), 231-234. PMID: 21534371.

Herrerias, C. T., Perrin, J. M., \& Stein, M. T. (2001). The child with ADHD: using the AAP Clinical Practice Guideline. American Academy of Pediatrics. American family physician, 63(9), 1803-1810. PMID: 11352293

Homer, C. J., Baltz, R. D., Hickson, G. B., Miles, P. V., Newman, T. B., Shook, J. E., . . . Shiffman, R. (2000). Clinical practice guideline: Diagnosis and evaluation of the child with attention-deficit/hyperactivity disorder. Pediatrics, 105(5), 1158-1170. https://doi.org/10.1542/peds.105.5.1158

Hurtig, T., Ebeling, H., Taanila, A., Miettunen, J., Smalley, S., McGough, J., . . . Moilanen, I. (2007). ADHD and comorbid disorders in relation to family environment and symptom severity. European child \& adolescent psychiatry, 16(6), 362-369. https://doi.org/10.1007/s00787-007-0607-2

Muanprasart, P., Traivaree, C., Arunyanart, W., \& Teeranate, C. (2014). Knowledge of attention deficit hyperactivity disorder and its associated factors among teachers in 3 large primary schools in Phra Nakorn Sri Ayutthaya Province, Thailand. J Med Assoc Thai, 97(2), S107-14. PMID: 25518183.

Nigg, J. T., \& Breslau, N. (2007). Prenatal smoking exposure, low birth weight, and disruptive behavior disorders. Journal of the American Academy of Child \& Adolescent Psychiatry, 46(3), 362-369. https://doi.org/10.1097/01.chi.0000246054.76167.44

Pham, H. D., Nguyen, H. B. H., \& Tran, D. T. (2015). Prevalence of ADHD in primary school children in Vinh Long, Vietnam. Pediatrics international, 57(5), 856-859. https://doi.org/10.1111/ped.12656

Pityaratstian, N., Booranasuksakul, T., Juengsiragulwit, D., \& Benyakorn, S. (2014). ADHD screening properties of the Thai version of Swanson, Nolan, and Pelham IV scale (SNAP-IV) and Strengths and Difficulties Questionnaire (SDQ). Journal of Psychiatric Association of Thailand, 59(2), 97-110.

Sasaluxnanon, C., \& Kaewpornsawan, T. (2005). Risk factor of birth weight below 2,500 grams and attention deficit hyperactivity disorder in Thai children. Journal-Medical Association of Thailand, 88(11), 1514. PMID: 16471095.

Swanson, J., Nolan, W., \& Pelham, W. E. (1992). The SNAP-IV rating scale. Irvine, CA: University of California at Irvine.

Thapar, A., \& Cooper, M. (2016) Attention deficit hyperactivity disorder. Lancet, 387(10024), 1240-1250. https://doi.org/10.1016/S0140-6736(15)00238-X

Thomas, R., Sanders, S., Doust, J., Beller, E., \& Glasziou, P. (2015). Prevalence of attention-deficit/hyperactivity disorder: a systematic review and metaanalysis. Pediatrics, 135(4), e994-e1001. https://doi.org/10.1542/peds.2014-3482

Trangkasombat, U. (2008). Clinical characteristics of ADHD in Thai children. Medical journal of the Medical Association of Thailand, 91(12), 1894. PMID: 19133526.

van der Meer, J. M., Oerlemans, A. M., van Steijn, D. J., Lappenschaar, M. G., de Sonneville, L. M., Buitelaar, J. K., \& Rommelse, N. N. (2012). Are autism spectrum disorder and attention-deficit/hyperactivity disorder different manifestations of one overarching disorder? Cognitive and symptom evidence from a clinical and population-based sample. Journal of the American Academy of Child \& Adolescent Psychiatry, 51(11), 1160-1172. https://doi.org/10.1016/j.jaac.2012.08.024 
Visanuyothin, T., Pavasuthipaisit, C., Wachiradilok, P., Arunruang, P., \& Buranasuksakul, T. (2013). The prevalence of attention deficit/hyperactivity disorder in Thailand. Journal of Mental Health of Thailand, 21(2), 66-75.

Wehmeier, P. M., Schacht, A., \& Barkley, R. A. (2010). Social and emotional impairment in children and adolescents with ADHD and the impact on quality of life. Journal of Adolescent Health, 46(3), 209-217. https://doi.org/10.1016/j.jadohealth.2009.09.009

Yajai Sitthimongkol, R. N., \& Apinuntavech, S. (2012). Predicting Factors for Risk of Depression in Adolescents with Learning Disorders. J. Med. Assoc. Thai., 95(11), 1480-4. PMID: 23252216.

\section{Copyrights}

Copyright for this article is retained by the author(s), with first publication rights granted to the journal.

This is an open-access article distributed under the terms and conditions of the Creative Commons Attribution license (http://creativecommons.org/licenses/by/4.0/). 